No.10_Dec2018|Số 10 - Tháng 12 năm 2018|p.92-98

TAP CHÍ KHOA HỌC ĐẠI HỌC TÂN TRÀO
ISSN: $2354-1431$

\title{
Vai trò của giảng viên trong xây dựng môi trường học tập tích cực tại các trường đại học và cao đẳng
}

\author{
Lê Đức Quảng ${ }^{a^{*}}$ \\ ${ }^{a}$ Truờng Cao đẳng Su pham Quảng Trị \\ *Email:quang_ld@qtttc.edu.vn
}

\section{Thông tin bài viết}

Ngày nhận bài:

11/10/2018

Ngày duyệt đăng:

$10 / 12 / 2018$

\section{Tù khoá:}

Vai trò; giảng viên; xây

dưng môi trường; môi

truòng hoc tập; hoc tập tích

cupc.

\section{Tóm tắt}

Nghiên cứu này nhằm mục đích: 1) Chỉ rõ tầm quan trọng của môi trường học tập đối với người học và trách nhiệm của giảng viên trong việc xây dựng bầu không khí học tập tích cực trong nhà trường để nâng cao chất lượng giáo dục. 2) Các yếu tố vật chất và tinh thần cơ bản tạo nên môi trường học tập tích cực trong nhà trường. 3) Những yếu tố chính và nhiệm vụ của giảng viên trong việc xây dựng môi trường học tập tích cực cho người học tại các trường đại học và cao đẳng. Đây được coi là một trong những yếu tố nội lực và ngoại lực rất quan trọng nhằm tạo hứng thú, động lực cho người học trong đào tạo học chế tín chỉ tại các trường đại học, cao đẳng hiện nay ở Việt Nam và rất phù hợp với $\mathrm{xu}$ hướng xây dựng môi trường học tập nhân văn của nhiều trường đại học trong khu vực và thế giới.

\section{1. Đặt vấn đề}

Quá trình dạy và học thực chất là hoạt động tương tác chủ yếu giữa hai chủ thể: người học chủ động đi tìm chân lý và người dạy hướng dẫn cách tiếp cận chân lý. Có rất nhiều các tác nhân bên ngoài làm ảnh hưởng đến hiệu quả của hoạt động này và một trong số đó phải kể đến chính là môi trường học tập. Môi trường xung quanh tác động tới người học, người dạy và hoạt động của họ trên hai phương diện sau: Một là, tác động từ phía bên ngoài các chủ thể, gồm toàn bộ môi trường vật chất xung quanh người học, gia đình, nhà trường và xã hội như: nhiệt độ, ánh sáng, âm thanh, cơ sở vật chất, thiết bị, đồ dùng dạy học. Hai là, tác động từ phía bên trong các chủ thể, gồm toàn bộ môi trường tinh thần như: tiềm năng, xúc cảm, giá trị, vốn sống, phong cách và nhân cách của người dạy để tạo được bầu không khí thân mật, vui vẻ, hợp tác trong lớp học nhằm chuẩn bị tốt nhất về tâm lí, kiến thức nền cho người học tham gia vào quá trình tương tác tích cực với các thành tố khác trong hoạt động dạy học để đồng hoá tri thức. Song không phải lúc nào sự tác động của các môi trường này đến hoạt động dạy học cũng diễn ra theo hướng tích cực, thuận chiều mà ngược lại có khi gây ra sự ức chế, sự mệt mỏi, chán nản cho người học trong thời gian dài đã ảnh hưởng xấu đến kết quả học tập của họ. Thực tế này đã buộc người dạy phải nhận thức rõ một điều là cần phải cải tạo tổng thể môi trường dạy học thì mới nâng cao hiệu quả dạy học một cách thường xuyên, bền vững trong nhà trường. Vì vậy, việc xây dựng môi trường học tập tích cực cho người học được xem là một vai trò và nhiệm vụ quan trọng của giảng viên trong các trường đại học và cao đẳng hiện nay.

\section{Nội dung}

\subsection{Phuơng pháp và công cu nghiên cứu}

Nghiên cứu này nhằm đánh giá vai trò của giảng viên trong công tác xây dựng môi trường học tập tích cực tại các trường đại học và cao đẳng - bằng việc phân tích tài liệu và các nghiên cứu liên quan của các tác giả trong và ngoài nước. Kết quả của nghiên cứu này dựa trên thông tin phỏng vấn chuyên gia QLGD bằng 
phương pháp phỏng vấn cấu trúc (Structured Interview) kết hợp điều tra khảo sát bằng bảng hỏi (Check List). Trong nghiên cứu này, các câu hỏi điều tra có giá trị IOC.Index là $0,80-1,00$ và có độ tin cậy toàn bộ là 0,96 .

\subsection{Tổng quan nghiên cứu lý thuyết}

\subsubsection{Khái niệm về môi truò̀ng học tập}

Theo Wichan Suwanwong [14, tr.12] - Nhà giáo dục Thái Lan, môi trường học tập là: môi trường trong nhà trường bao gồm các yếu tố khác nhau nhằm khuyến khích người học học tập phát triển bản thân về mọi mặt như nhà trường đẹp đẽ, mát mẻ, an toàn, trật tự, có bầu không khí dễ chịu, đầy đủ các phương tiện, thiết bị giúp phát triển và nâng cao việc học tập của sinh viên.

Kiều Thị Bích Thủy và Nguyễn Trí $[15$, tr.13-14] cũng cho rằng môi trường học tập gồm tập hợp các yếu tố ảnh hưởng đến việc dạy và học. Môi trường học tập là nơi diễn ra quá trình học tập của trẻ, bao gồm: môi trường vật chất và môi trường tinh thần.

- Môi trường vật chất: Là toàn bộ không gian (cả trong hoặc ngoài phòng học), nơi diễn ra quá trình dạy học, mà ở đó có các yếu tố như bảng, bàn ghế, ánh sáng, âm thanh, không khí, cách sắp xếp không gian phòng học...

- Môi trường tinh thần: Là toàn bộ mối quan hệ tác động qua lại giữa giảng viên, sinh viên, nhà trường, gia đình và cộng đồng.

Từ các khái niệm trên ta có thể kết luận: môi trường học tập bao gồm đầy đủ các yếu tố vật chất và tinh thần ở bên trong nhà trường nhằm khuyến khích cho người học học tập và phát triển toàn diện bản thân. Bao gồm cảnh quan môi trường trong nhà trường thực sự đẹp, có tính thẩm mỹ cao, thoáng mát, an toàn, trật tự, có bầu không khí dễ chịu, thân thiện trong các mối quan hệ thầy - trò, có đầy đủ phương tiện, thiết bị dạy học hiện đại... để phát triển và nâng cao việc học tập cho người học. Đối với các trường cao đẳng và đại học, việc xây dựng một môi trường học tập tốt không chỉ kích thích sự say mê, ham thích học tập và rèn luyện, phát triển và hoàn thiện bản thân sinh viên mà còn hoàn thành được mục tiêu đào tạo của nhà trường.

2.2.2. Những tiêu chí co bản của môi truờng học tập tích cục trong truờng học

Dựa trên những nghiên cứu khoa học về tâm lý và giáo dục học cho thấy: ở độ tuổi 17-18 cơ thể sẽ tiếp tục phát triển nếu bộ não được kích thích bởi một môi trường tốt. Đặc biệt nếu một người đã từng tham gia học tập ở nhà trường hoặc có một trình độ học vấn cao, sẽ giúp gia tăng chỉ số IQ từ kết quả học tập. Các nhà giáo dục rất quan tâm và coi trọng việc tạo dựng một môi trường thuận lợi cho sự học hỏi, tìm tòi của người học vì nó sẽ giúp cho trí não của họ tiếp tục phát triển. Và cũng chính môi trường trở thành chất kích thích để con người thể hiện những hành vi, thái độ sống của mình đối với môi trường xung quanh. Các nhà tâm lý học phân chia môi trường thành 2 loại sau:

1) Môi trường bên ngoài bao gồm các dạng vật chất vô cơ và hữu cơ cụ thể như đồ đạc, con người và động vật, v.v. cũng như những thứ trừu tượng, vô hình như phong tục, truyền thống ở bên ngoài cơ thể con người. Nếu môi trường này kích thích cho con người thể hiện hành vi, gọi là kích thích bên ngoài.

2) Môi trường bên trong bao gồm các hoạt động của các cơ quan nội tạng bên trong của con người, như đói và khát. Nếu môi trường này kích thích cho con người thể hiện hành vi, gọi là kích thích bên trong.

Phân tích quan điểm về môi trường học tập tích cực của hai Nhà Giáo dục Thái Lan: Tanet Khamcot [7, tr.44] và Wichit Thepprasit tác giả cho rằng việc xây dựng một môi trường phù hợp với lứa tuổi và trình độ của người học là yếu tố khuyến khích người học ham muốn học tập để đạt hiệu quả tốt hơn. Môi trường học tập được coi là tốt, tích cực, lý tưởng thể hiện ở nhiều phương diện dưới đây:

Thư nhất, về muc đích đào tạo: Mục đích quan trọng của giáo dục suy đến cùng là giúp cho người học có được một nhân cách tốt. Điều đó được thể hiện qua lời nói, tinh thần mẫu mực, có đạo đức tư cách, có những hành vi, hành động phù hợp với chuẩn mực đạo đức của xã hội được xã hội thừa nhận. Để hình thành hành vi tốt hoặc thay đổi hành vi chưa tốt của sinh viên theo mục đích mong muốn đòi hỏi phải có thời gian và phụ thuộc vào nhiều yếu tố, trong đó môi trường học tập cũng là một yếu tố giúp thay đổi hoặc tác động đến hành vi của sinh viên. Đó chính là môi trường học tập có bầu không khí ấm áp, thân thiện, dân chủ, thừa nhận những ý kiến lẫn nhau, giải quyết vấn đề một cách hợp lý, v.v.

Thứ hai, về chương trình giảng dạy: Đó là trang bị một hệ thống những tri thức cơ bản, cốt lõi của ngành học và kỹ năng thực hành nghề để giúp người học tích lũy được nhiều kinh nghiệm mong muốn. Kinh nghiệm học tập phụ thuộc vào môi trường học tập. Thông thường sự hiểu biết và kinh nghiệm của người học sẽ được hình thành từ việc tiếp xúc, quan hệ với những yếu tố bên ngoài mà có những kích thích tạo cảm xúc nhất định cho người học. Vì vậy, nếu chúng ta muốn sinh viên tiếp thu những kinh nghiệm học tập tốt, thì 
trước hết cần trang bị cho người học một môi trường học tập tốt, bởi chính môi trường học tập hoàn hảo sẽ tạo nên những kinh nghiệm quý báu cho người học sau này.

Thư ba, về năng lực su pham của giảng viên: Giảng viên phải có năng lực sư phạm toàn diện về nhiều mặt để tạo được ấn tượng đẹp và mạnh cho người học, biết động viên người học có hứng thú, có động lực trong học tập để thay đổi thái độ theo chiều hướng tích cực, hài lòng trong việc học giúp đạt được thành tích tốt hơn. Việc người dạy biết truyền cảm hứng cho người học, làm cho họ cảm thấy hài lòng, muốn được học, được biết là yếu tố quan trọng để quá trình dạy học đạt hiệu quả cao.

Thư tu, về kỷ cuoong, kỷ luật trong nhà truờng: Một môi trường học tập tốt sẽ góp phần kiểm soát lớp học, giúp người học biết phục tùng tổ chức, tuân thủ kỷ luật. Bởi môi trường học tập sẽ quy định phạm vi học tập, làm cho bầu không khí khác với những hoạt động khác. Lẽ dĩ nhiên là người học khi được học tập trong một môi trường tốt, có nề nếp, quy củ bao giờ cũng sẽ thực hiện kỷ luật tốt hơn những người học ở môi trường học tập xấu, đầy rẫy sự tiêu cực. Nhờ đó mà việc kiểm soát lớp học có thể nhanh chóng, chính xác và dễ dàng hơn cho giáo viên.

Thư năm, về mối quan hệ giũa giảng viên với sinh viên và sinh viên với sinh viên: Môi trường học tập tích cực là phải tạo ra một mối quan hệ tốt giữa giảng viên và sinh viên. Dù trong không gian, địa điểm là lớp học hay ở ngoài lớp đều phải tạo cảm giác thoải mái, thân thiện giữa giảng viên với sinh viên. Vị trí của giảng viên không nhất thiết lúc nào cũng ở phía trên bục giảng, có thể ở vị trí trung tâm của lớp học để giúp tư vấn, hướng dẫn cho sinh viên, cũng có thể di chuyển đến gần sinh viên, giúp cho người dạy tiếp xúc với người học thuận tiện. Nhờ vậy, giảng viên gần gũi với sinh viên hơn, có điều kiện tìm hiểu tính cách và hành vi của từng sinh viên được tốt hơn, giúp sinh viên bớt lo sợ, mạnh dạn phát biểu ý kiến, có thái độ hợp tác tốt đối với giảng viên. Môi trường học tập tốt sẽ tác động đến việc dạy học đạt hiệu quả cao làm cho người học háo hức tìm tòi, nghiên cứu hay thực hiện các hoạt động chuyên môn chăm chú và tập trung hơn. Một môi trường học tập tốt về mặt tinh thần phải có đặc điểm là tạo được cảm giác ấm áp, thân thiện giữa các thành viên trong lớp học, điều này sẽ giúp cho người học tìm thấy niềm vui trong học tập.

Thú sáu, về nguồn tài nguyên, trang thiết bị và co sơ vật chất: Nhà trường phải xây dựng được nguồn tài nguyên học tập đa dạng, phong phú, đồng thời thấy rõ tầm quan trọng của các bộ phận phục vụ hoạt động chuyên môn như trung tâm học thuật - thư viện, trung tâm thiết bị đồ dùng dạy - học... trong việc giúp cho sinh viên và giảng viên có thể sử dụng để khám phá, tích lũy kiến thức bất kỳ lúc nào nhằm khuyến khích việc tự học và tổ chức tốt hoạt động dạy học theo hình thức lấy người học làm trung tâm. Các trung tâm này phải thường xuyên bổ sung, cập nhật các nguồn tài nguyên học tập theo hướng chuyên ngành, đa ngành để phục vụ cho nhu cầu của người học. Ngoài ra, các phòng học phải có trang thiết bị và tài liệu dạy học đầy đủ, hiện đại tạo cho người học sự hứng thú học tập, người dạy cũng hứng thú giảng dạy. Những phương tiện vật chất này giúp hỗ trợ và khuyến khích cho hoạt động dạy - học thực hiện thuận tiện, nhanh chóng theo kế hoạch đã đặt ra. Môi trường học tập tốt còn phải có cơ sở vật chất đầy đủ, phù hợp với độ tuổi để giúp giảm bớt sự căng thẳng, chán nản, mệt mỏi trong cơ thể của người học như là bàn ghế phải có kích thước phù hợp với cơ thể của người học, càng đẹp càng tốt, giúp cho người học ngồi, đi ra đi vào thoải mái, ngồi lâu không mỏi lưng. Ánh sáng trong lớp học phải đủ sáng ở mọi ví trí ngồi của người học, không quá gắt, không quá yếu để không tạo ra sự mệt mỏi cho đôi mắt. Ngoài ra, nó cũng thúc đẩy sự phát triển về mặt thể chất, tình cảm, xã hội và trí tuệ của người học. Bảng chống lóa cho dù người học ngồi ở các vị trí xa hay gần khác nhau. Dùng phấn không bụi hoặc bút dạ xóa được. Cửa sổ đóng mở phải chắc chắn, có rèm che để chống ánh nắng nóng, gió lạnh, gió to lùa vào và đủ ngăn được ánh sáng trắng ngoài lớp học khi giờ học có sử dụng máy chiếu overheat. Quạt hay hệ thống điều hòa phải đáp ứng được nhiệt độ nhất định của lớp học.

Từ các ý kiến của các nhà chuyên môn trên, ta có thể khẳng định rằng: "môi trường tích cực" trong nhà trường là tập hợp của rất nhiều yếu tố vật chất và tinh thần để phục vụ ngày càng tốt hơn hoạt động dạy - học trong nhà trường. Nó được xem là nhân tố bên ngoài và bên trong quan trọng của mỗi cá nhân nhằm thúc đẩy sinh viên tự giác, siêng năng và có trách nhiệm trong học tập, trong thực hành nghề một cách thật sự nghiêm túc. Đồng thời giúp người học phát triển tốt về tư duy, ý thức và nhân cách để đạt được thành công trên con đường học vấn.

2.3. Vai trò của giảng viên trong xây dụng môi truò̀ng học tập tích cục

2.3.1. Sụ cần thiết phải xây dụng môi trừ̀ng học tập tích cục 
Nhiều nhà nghiên cứu giáo dục đã đưa ra ý kiến về lĩnh vực xây dựng môi trường học tập tích cực, như Krug [8, tr.213] cho rằng môi trường học tập của nhà trường thể hiện giá trị của việc học tập và là bầu không khí khuyến khích vươn đến sự thành công. Giảng viên có trách nhiệm tạo dựng một bầu không khí trong dạy và học nhằm cung cấp năng lượng cho người học. Có rất nhiều cách để thực hiện điều đó, như xây dựng một môi trường an toàn và tổ chức các hoạt động dạy - học lấy người học làm trung tâm.

Còn Marsh [12, tr.116] cho rằng giảng viên cần quan tâm đến sự phát triển của môi trường làm việc, an toàn và trật tự, tăng cường sự hợp tác giữa giảng viên và sinh viên. Xây dựng mối quan hệ giữa các tổ chức bên ngoài và nhà trường hoặc giữa gia đình và nhà trường. Trùng hợp ý kiến của Hoy and Hoy [4, tr.238] là: Vai trò quan trọng nhất của giảng viên là lãnh đạo chuyên môn (Instructional leader), chịu trách nhiệm về sự phát triển môi trường của nhà trường để tạo hiệu quả cho công tác dạy - học tốt nhất.

Southworth [13, tr.325] và Marsh [12, tr.19] cho rằng giảng viên phải quan tâm đến văn hóa của nhà trường, tạo dựng môi trường học tập thuận lợi, giảm các quy định, giảm gánh nặng thủ tục giấy tờ, nhằm thúc đẩy không khí chuyên môn. Sự hiện diện của giảng viên trong nhà trường một cách thường xuyên là niềm động viên tinh thần đối với sinh viên.

Dimmock and Walker nêu rằng việc xây dựng môi trường của nhà trường nhằm thuận lợi trong công việc dạy - học có mối quan hệ lẫn nhau. Vì vậy, giảng viên là lãnh đạo chuyên môn cần tạo dựng một bầu không khí và văn hóa của nhà trường nhằm mục đích ưu tiên cho việc dạy và học [2].

Ngoài ra, Hoy and Hoy [3, tr.312] cũng đề cập đến môi trường của trường học có ảnh hưởng trực tiếp và gián tiếp đến tư tưởng, hành vi và công việc của giảng viên.

Mặt khác Hughes, Ginnett và Curphy [5. tr. 60] cho rằng sự trao đổi, phản ánh thông tin là rất quan trọng bởi vì nó giúp cho giảng viên thể hiện các quan điểm khác nhau, có cái nhìn đa chiều trong phạm vi một vấn đề.

Blasé and Blasé [1, tr.252] đã thực hiện nghiên cứu cho thấy rằng: người lãnh đạo chuyên môn theo dõi, quản lý kết quả giảng dạy của giảng viên, giúp tăng cường sự phản ánh kết quả hoạt động chuyên môn của giảng viên. Giảng viên có vận dụng các lý thuyết mới, phương pháp giảng dạy mới đáp ứng nhu cầu đa dạng của người học. Chuẩn bị bài dạy, xây dựng kế hoạch cẩn thận, dũng cảm vượt qua rủi ro và quan tâm đến quy trình giảng dạy nhiều hơn.

Jazzar and Algozzine [6, tr.224] cho biết rằng các trường học tại Hoa kỳ đã xây dựng mối quan hệ hợp tác với các gia đình của sinh viên và cộng đồng để nỗ lực hỗ trợ sự phát triển nhà trường và thành tích học tập của sinh viên. Chứng tỏ rằng việc xây dựng mối quan hệ tốt giữa giảng viên với sinh viên, phụ huynh và cộng đồng là vô cùng quan trọng.

Còn McEwan [11, tr.331]; Lashway [9, tr.219] đã phát biểu bổ sung như sau: người giảng viên có năng lực lãnh đạo chuyên môn là người xây dựng và duy trì mối quan hệ tốt với các sinh viên, đồng nghiệp, phụ huynh, kể cả cộng đồng, nhằm khuyến khích cộng đồng hỗ trợ nhà trường đạt được sự thành công. Ngoài ra Nguyễn Thị Ngọc Liên [10, tr.131] cho rằng: hơn ai hết trong nhà trường, giáo viên chính là người xây dựng nền văn hóa nhà trường, tạo dựng bầu không khí và môi trường làm việc chuyên nghiệp, trách nhiệm và hiệu quả. Mặt khác, họ đóng vai trò quan trọng trong việc hình thành nên văn hóa tổ chức của lớp học. và Phạm Quang Tiệp [16, tr.36] lại nêu rằng: Môi trường dạy học ở đây được xem xét một cách toàn diện, đó là tất cả những yếu tố bên trong và bên ngoài người học và người dạy, có tác động, ảnh hưởng trực tiếp hoặc gián tiếp lên hoạt động của họ. Sự tác động của môi trường cũng theo hai chiều hướng dương tính và âm tính.

Trên cở sở phân tích các ý kiến của các chuyên gia bàn ở nhiều phương diện, góc độ khác nhau về vai trò của môi trường học tập tích cực đối với hiệu quả học tập của người học đã chứng tỏ rằng việc xây dựng môi trường học tập tích cực là điều tất yếu đối, là vô cùng quan trọng với hoạt động dạy - học trong các nhà trường hiện nay. Sự phát triển nhà trường có một vấn đề cần quan tâm đó là việc xây dựng môi trường học tập tích cực cho người học và cũng là một nhiệm vụ cơ bản của giảng viên trong thời đại ngày nay. Một môi trường tốt là một yếu tố giúp người học phát triển, an toàn, có động lực, cảm thấy hạnh phúc, sẵn sàng khám phá kiến thức. Ngược lại nếu một nhà trường không quan tâm đến môi trường, hoặc không thấy tầm quan trọng của việc xây dựng môi trường, sẽ làm cho mọi người cả trong và ngoài nhà trường thiếu sự tương tác tốt, có bầu không khí nhàm chán, thiếu sự ấm áp và bầu không khí thân thiện, thiếu niềm tin về nhà trường, làm cho yếu tố của câu nói "cơ sở học tập" thiếu sự hoàn chỉnh.

2.3.2. Các yếu tố co bản về vai trò của giảng viên trong xây dụng môi truò̀ng học tập tích cụcc 
Sau khi nghiên cứu và phân tích quan điểm của các nhà giáo dục trong nước và nước ngoài (phần 2.3.1) bàn về việc xây dựng môi trường học tập tích cực, tác giả nhận thấy có 5 yếu tố cơ bản về vai trò của giảng viên trong xây dựng môi trường học tập tích cực theo bảng sau:

Bảng 1: Các yếu tố cơ bản về vai trò của giảng viên trong xây dựng môi trường học tập tích cực.

\begin{tabular}{|c|c|c|c|c|c|c|c|c|c|c|c|c|c|c|c|c|c|}
\hline \multirow[b]{2}{*}{ Yểu tố } & \multicolumn{17}{|c|}{ Nguồn tài liệu } \\
\hline & 矛 & 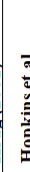 & $\frac{1}{2}$ & 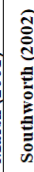 & $\begin{array}{l}0 \\
0 \\
0\end{array}$ & & $\begin{array}{l}0 \\
0 \\
0 \\
0 \\
0 \\
0 \\
0 \\
0 \\
0\end{array}$ & $=$ & $\frac{1}{4}$ & & & & | & & : & نे. & 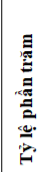 \\
\hline $\begin{array}{l}\text { 1. GV cần quan tâm } \\
\text { xây dựng môi trường } \\
\text { học tập. }\end{array}$ & $v$ & v & $\sqrt{ }$ & & $\checkmark$ & $\checkmark$ & v & v & v & $v$ & 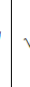 & . & v & $\checkmark$ & & 12 & $\begin{array}{r}85, \\
0\end{array}$ \\
\hline $\begin{array}{l}\text { 2. GV cần trao đồi ý } \\
\text { truơng và phản ánh } \\
\text { thông tin. }\end{array}$ & & $\checkmark$ & $\sqrt{ }$ & $v$ & $v$ & $\checkmark$ & $v$ & v & & & v & . & v & $v$ & $v$ & 11 & $\begin{array}{r}78, \\
0\end{array}$ \\
\hline $\begin{array}{l}\text { 3. GV cần xây dựng } \\
\text { và duy trì mối quan } \\
\text { hệ tốt giữa giảng } \\
\text { viên, sinh viên và } \\
\text { cộng đồng. }\end{array}$ & $v$ & v & & $\sqrt{ }$ & v & $\checkmark$ & v & v & $v$ & $v$ & & . & v & & & 10 & $\begin{array}{r}71, \\
0\end{array}$ \\
\hline $\begin{array}{l}\text { 4. GV cần xây dựng } \\
\text { văn hóa học tập trong } \\
\text { nhà trường. }\end{array}$ & & $\checkmark$ & v & & & & & & & & & & & & $v$ & 3 & $\begin{array}{c}21, \\
0\end{array}$ \\
\hline $\begin{array}{l}\text { 5. GV cần tạo động } \\
\text { lực và tinh thần cho } \\
\text { người học. }\end{array}$ & & & & & & & & & $\sqrt{ }$ & & & & & $v$ & & 2 & $\begin{array}{c}14, \\
0\end{array}$ \\
\hline
\end{tabular}

Căn cứ vào bảng 1 cho thấy có nhiều chuyên gia giáo dục đồng quan điểm về các yếu tố cơ bản về vai trò của giảng viên trong xây dựng môi trường học tập tích cực, với tỷ lệ $50 \%$ trở lên đó là các yếu tố:

1) Giảng viên cần quan tâm xây dựng một môi trường học tập.

2) Giảng viên cần trao đổi ý tưởng và phản ánh thông tin.

3) Giảng viên cần xây dựng và duy trì mối quan hệ tốt giữa giảng viên, sinh viên và cộng đồng.

Từ đó khẳng định rằng, người có vai trò và trách nhiệm lớn trong việc xây dựng môi trường học tập tích cực không ai khác chính là đội ngũ giảng viên. Chỉ khi nào đội ngũ giảng viên cùng nhau hợp tác xây dựng được môi trường học tập tích cực, hoàn thành tốt các vai trò trên thì mới tạo được động lực thực sự cho người học học tập thoải mái và đạt hiệu quả cao trong phương thức đào tạo tín chỉ, lấy người học làm trung tâm để phát huy hết năng lực người học trong quá trình chiếm lĩnh tri thức để kinh nghiệm làm việc sau này.

\footnotetext{
2.3.3. Kết quả điều tra khảo sát về vai trò của giảng viên trong xây dụng môi trừ̀ng học tập tích cục
}

Sau khi nghiên cứu và phân tích ý kiến của các chuyên gia đề cập đến các yếu tố cơ bản về vai trò của giảng viên trong việc xây dựng môi trường học tập tích cực, để đi đến khẳng định giảng viên có vai trò rất lớn trong nhiệm vụ này tác giả đã tiến hành điều tra, khảo sát 291 giảng viên ở các trường đại học và cao đẳng khu vực miền Trung để tìm hiểu về nhận thức của họ đối với vai trò của giảng viên trong công tác xây dựng môi trường học tập tích cực bởi đây là một yếu tố quan trọng góp phần đánh giá năng lực của giảng viên ở các trường đại học và cao đẳng trong thời đại ngày nay. Kết quả điều tra thể hiện ở bảng 2 .

Bảng 2: Vai trò của giảng viên trong xây dựng môi trường học tập tích cực.

\begin{tabular}{|c|c|c|c|c|}
\hline \multirow{2}{*}{$\begin{array}{c}\text { Yếu } \\
\text { tố }\end{array}$} & \multirow{2}{*}{$\begin{array}{l}\text { Vai trò của giảng viên trong xây dụng môi tường } \\
\text { lọ̣c tập tích cực }\end{array}$} & \multicolumn{3}{|c|}{ Gía trị thống kê $(\mathrm{N}=291$} \\
\hline & & $\overline{\mathrm{x}}$ & S.D. & Mức độ \\
\hline 1. & $\begin{array}{l}\text { Giàng viên cần quan tâm xây dựng môi trường học } \\
\text { tập. }\end{array}$ & 3,79 & 0,36 & Tốt \\
\hline 2. & $\begin{array}{l}\text { Giàng viên cần trao đồi ý tường và phản ánh thông } \\
\text { tin. }\end{array}$ & 3,69 & 0,35 & Tốt \\
\hline 3. & $\begin{array}{l}\text { Giảng viên cần xây dựng và duy trì mối quan hệ tốt } \\
\text { giữa giảng viên, sinh viên và cộng đồng. }\end{array}$ & 3,57 & 0,30 & Tót \\
\hline & Tống cộng & 3,68 & 0,26 & Tốt \\
\hline
\end{tabular}

Kết quả ở bảng 2 cho thấy: Các yếu tố về vai trò của giảng viên trong xây dựng môi trường học tập tích cực của các chuyên gia đưa ra đều được các giảng viên lựa chọn và nhất trí cao vì cả 3 yếu tố khảo sát đều ở mức độ Tốt. Điều đó càng chứng tỏ xây dựng môi trường học tập tích cực là một nhiệm vụ quan trọng, là một nhiệm vụ tất yếu trong hoạt động giảng dạy của giảng viên để nâng cao chất lượng giáo dục và tạo thương hiệu cho các trường đại học, cao đẳng hiện nay. Với kết quả khảo sát ở mức độ Tốt $(\overline{\mathrm{X}}=3,68)$ của bảng này một lần nữa đã khẳng định rằng giảng viên có vai trò cực kỳ quan trọng trong xây dựng môi trường học tập tích cực. Từ kết quả nghiên cứu trên đây tác giả rút ra các nhận định sau:

Một là, giảng viên có vai trò quan trong trong xây dựng môi trường học tập tích cực tại các trường đại học và cao đẳng.

Hai là, các trường đại học và cao đẳng cần phải chú trọng, đề cao, khuyến khích các giảng viên xây dựng môi trường thuận lợi cho việc dạy và học, thiết kế trang trí lớp học đẹp, tạo sự hấp dẫn cả trong và ngoài lớp học nhằm thu hút người học.

Ba là, mỗi giảng viên phải ý thức được việc lập kế hoạch sử dụng phương tiện và tài nguyên học tập, tạo điều kiện cho sinh viên được thực hành thực sự nhằm giúp sinh viên tự khám phá tri thức. Giảng viên cần lựa 
chọn phương tiện và tài nguyên phù hợp với các hoạt động dạy học và lứa tuổi của người học.

Bốn là, mỗi giảng viên phải là một tấm gương sáng về ứng xử theo đúng chuẩn mực của văn hóa học đường và cũng chính là người có vai trò quan trọng trong việc xây dựng môi trường văn hóa học đường, tạo bầu không khí và môi trường làm việc một cách chuyên nghiệp, có trách nhiệm, hiệu quả.

Năm là, cán bộ quản lý và lãnh đạo nhà trường cần tập huấn hàng năm về kỹ năng phát triển năng lực lãnh đạo chuyên môn cho giảng viên nhằm giúp cho họ làm tốt công tác xây dựng môi trường học đường tích cực để tăng sự tương tác giữa người dạy và người học nhằm khuyến khích, động viên sinh viên học tập mọi lúc mọi nơi. Ngược lại, giảng viên cũng cần phải hợp tác với cán bộ quản lý nhà trường để tạo ra một môi trường học tập tích cực. Có như vậy sinh viên mới có cơ hội thường xuyên bổ sung, tích lũy kiến thức, phát triển tư duy, rèn luyện tính cách, sống có trách nhiệm với công việc và thành công trong học tập.

\section{Kết luận}

Với xu hướng dạy học hiện đại lấy người học làm trung tâm để phát huy năng lực người học nhằm tạo ra một nguồn nhân lực có chất lượng, nhạy bén, thích ứng với mọi sự biến đổi của thời đại số, cuộc sống số thì yếu tố môi trường trong dạy học ngày nay cần được quan niệm lại, nhìn nhận một cách đầy đủ và toàn diện hơn. Môi trường được xem là một trong ba thành tố quan trọng (cùng với người học và người dạy) cấu trúc nên hoạt động dạy học. Sự tác động qua lại giữa ba thành tố đó đã tạo ra sự vận động, phát triển của hoạt động dạy học, từ đó tạo nên sự phát triển không chỉ ở người học mà cả người dạy và môi trường. Thực tiễn dạy học ngày nay cho thấy, các yếu tố thuộc môi trường vật chất được cải thiện đáng kể, tuy nhiên các yếu tố thuộc môi trường tâm lý chưa phát triển tương xứng với những đòi hỏi của dạy học theo hướng tương tác để tạo ra hiệu quả thực sự trong quá trình dạy học. Vì vậy, mỗi giảng viên các trường đại học, cao đẳng cần có kiến thức về môi trường học đường và ý thức trách nhiệm xây dựng môi trường học tập tích cực trong nhà trường để nâng cao chất lượng giảng dạy của chính mình nói riêng và của trường mình nói chung. Đây còn là một tiêu chí quan trọng để đánh giá năng lực của giảng viên. Điều này càng trở lên quan trọng trong thời gian tới, khi thang bậc lương của giảng viên được tính trên cơ sở dựa vào vị trí công tác và hiệu quả làm việc của mỗi giảng viên chứ không dựa vào thời gian công tác của họ.

\section{TÀI LIỆU THAM KHẢO}

[1] Blasé, J \& Blasé, J. (2009). Principals' instructional leadership and teacher development: Teachers' perspectives. Educational Administration Quarterly, 35(3), 349-378.

[2] Dimmock, C., \& A. Walker. (2005). Educational Leadership: Culture and Diversity. Gateshead: Athenaeum Press.

[3] Hoy, A. W., \& W. K. Hoy. (2006). Instructional Leadership: A Learning-Centred Guide. Boston: Allyn and Bacon.

[4] Hoy, R.C., \& Hoy, D.A. (2003). Organization behavior. San Francisco: Jossey-Bass.

[5] Hughes, Richard L. Ginnett, Robert C. and Curphy, Gordon J. (2009). Leadership: Enhancing the Lessons of Experience. Boston: McGraw-Hill.

[6] Jazzar, Michael and Algozzine, Bob. (2010). Keys to Successful 21st Century Educational Leadership. Boston: Pearson Education.

[7] Tanet Khamcot (2012). Tổng hợp các bài báo học thuật. NXB Nakhon Pathom-Thái Lan.

[8] Krug, S. (2001). Instructional leadership: A constructivist perspective. Educational Administration Quarterly, 28 (3), 430-443.

[9] Lashway, Larry. (2012). Developing Instructional Leaders. Retrieved February 10, 2013. from http://www.vtaide.com/png/ERIC/DevelopingInstructional-Leaders.html.

[10] Nguyễn Thị Ngọc Liên. Tăng cường vai trò lãnh đạo của giảng viên - giải pháp nâng cao tính tích cực, chủ động và năng lực tự học của giảng viên trong nhà trường hiện nay. Kỷ yếu hội thảo nâng cao năng lực tự hoc tụ nghiên cúu cho GVPT, trừ̀ng ĐHSP thành phố HCM, (2013), pp. 125-134.

[11] McEwan, E. K. (2010). Seven Steps to Effective Instructional Leadership. California: Corwin Press, inc.

[12] Marsh, D. (2001). Educational Leadership for the 21st century: Integrating three emerging perspectives. Paper presented at American Education research Association (Chicago, IL, March 24-28, 1997).

[13] Southworth, E.H. (2002). Leader and leadership process. Boston: Irwin / McGraw-Hill.

[14] Wichan Suwanwong (2016). Xây dưng môi trường trong truòng Benchamaratrungsarit 2 theo nhận thưc 
của giáo viên. Luận văn Thạc sĩ Quản lý giáo dục trường Đại học Bunrapha-Thái Lan.

[15] Kiều Thị Bích Thủy và Nguyễn Trí (2015). Xây dưng môi truờng học tập thân thiện. Tài liệu do Bộ GD-ĐT xuất bản.
[16] Phạm Quang Tiệp (2013). Dạy hoc dưa vào tuoong tác trong đào tạo Giáo viên Tiểu học trình độ Đại học. Luận án Tiến sĩ Khoa học Giáo dục,Viện Khoa học Giáo dục Việt Nam.

\section{The role of lecturers in building a positive learning environment at universities and colleges}

Le Duc Quang

\section{Article info}

Recieved:

$11 / 10 / 2018$

Accepted:

10/12/2018

Keywords:

Role; Lecturers; Environment building; Study environment; Active learning

\begin{abstract}
This study aims to: 1) Identify the importance of the learning environment for learners and the responsibilities of teachers in building a positive learning atmosphere at school to improve the quality of education. 2) Basic physical and mental factors create a positive learning environment at school. 3) Key elements and duties of teachers in building a positive learning environment for learners at universities and colleges. This is considered as one of the important internal and external factors to create excitement and motivation for learners in the credit-based training system at universities and colleges in Vietnam and in line with the trend of building a humanistic learning environment for many universities in the region and in the world.
\end{abstract}

